\title{
Attainment of Puberty in Pigs under Local Managemental Conditions
}

\author{
A. Chakraborty*, B. C. Deka and L. K. Nath \\ Krishi Vigyan Kendra, Lakhimpur, Assam Agricultural University, India \\ *Corresponding author
}

\section{A B S T R A C T}

\section{Keywords}

Age at attainment puberty, Farmers income, Feeding

Article Info

Accepted:

22 March 2020

Available Online:

10 April 2020
The objective of the study was to assess the variability in the age at attainment puberty of growing pigs under intensive rearing practices and local managemental conditions in the Krishi Vigyan Kendra, Lakhimpur adopted village for doubling farmer's income. 15 nos. of weaned Hampshire cross female pigs made the treatment group while 15 nos. of local pigs constituted the control group. The animals were reared under intensive rearing system with locally made pig sty. Feeding of the animals was done with equal amounts of kitchen waste and concentrated feed. To determine the age at puberty, individual animals were exposed to boar and the behavioural and physical signs were observed. Statistical analysis revealed significant difference $(\mathrm{P}<0.01)$ in the mean age at puberty between treatment and the control group.

\section{Introduction}

It is a well-known fact in the swine industry that early attainment of puberty is a key factor in minimizing costs associated with rearing replacement gilts. However it has been seen that despite domestication, the reproductive performance of female pigs exhibits strong seasonal trends. Pig is rated as one of the best meat producing animals in the world and pig industry is evolving continuously, but in spite of the huge contribution by the piggery sector in NE region neither the pork production nor the per capita pork availability has increased. There is a huge gap between demand and production. This is mainly due to rearing of non-descript local pig breed with poor productive and reproductive performance with traditional managemental practice (Shyam et al., 2017). Therefore good breed introduction as well as upgradation of the local breeds can serve as an important tool in bridging the gap. Hence, the present study was undertaken to assess the performance of Hampshire cross pigs under local managemental conditions. 


\section{Materials and Methods}

A total of 30 numbers of weaned, healthy and uniform sized female pigs were chosen. Out of which 15 were crossbred (Hampshire X Assam local) (Treatment group) and 15 numbers were non-descript local pigs (Control). The selected animals were kept under intensive housing system and were fed with equal amounts of kitchen waste with locally available feedstuff comprising of banana tuber, azolla, etc and concentrated feeds.

To determine the age at puberty individual animals were exposed to boar and the behavioral and physical signs were observed.

\section{Statistical analysis}

Data were analysed using PRISM software. Different parameters are presented as mean \pm SE. Significance was assessed through ANOVA and level of significance was set at $\mathrm{P}<0.01$.

\section{Results and Discussion}

Statistical analysis revealed significant difference $(\mathrm{P}<0.01)$ between treatment with $171.7 \pm 1.675$ and the control group with198.7 \pm 3.13 as mean age at puberty (Table 1 and Fig. 1).

Krikwood and Thacker (1988) also recorded the age at puberty as 150 days in Yorkshire $x$ Landrace gilts when fed $3 \mathrm{~kg}$ of diet per day from 120 days of age to onset of puberty (control). On the other hand, when gilts were fed only $2.0 \mathrm{~kg}$ per day they exhibited pubertal oestrus at 165 days of age (restricted). In 3rd group they fed $2.00 \mathrm{~kg}$ per day from 120 to 150 days of age, but increased thereafter to $3.5 \mathrm{~kg}$ per day until mated (flushed) and recorded age at puberty as 165 days. Similar finding was reported by
Lo et al., (1985) who made an experiment to see the effect of reproductive performance of gilts by different feeding methods during growing period. Female piglets were randomly divided into 3 groups. Group 1 was offered feed ad lib., whereas Group 2 and 3 offered 90 and 70 per cent of ad lib. Feed intake respectively from 20 to $90 \mathrm{~kg}$ body weight. Age at puberty averaged 166.2, 167.3 and 174.3 days respectively $(\mathrm{p}<0.05)$, and body weight at puberty $88.8,89.2$ and $80.3 \mathrm{~kg}$ Group 3 vs. Group 1 and $2(\mathrm{p}<0.01)$. Also the findings are in close proximity with the findings of Mavrogenis and Robison (1976) who reported that gilts born in fall reached puberty at younger age and a lower weight than those born in spring.

Robertson et al., 1951a found that Chester white gilts when compared to Poland china were 11 days older at puberty when raised on pasture $(\mathrm{p}<0.01)$ however no difference between breeds were found when grown in dry lots indicating a possible genotype by environment interaction for age at puberty. Thompson and Savage, 1978 and Brooks and Cole 1970 opined that the presence of boar with gilts reduces the mean age at puberty.

The response to boar stimuli appears to be related more to the age than the weight of the gilt as opined by Hughes and Cole, 1976, generally the younger the gilts are when exposed to a boar the lesser the degree of stimulation (as indicated by the number of days of exposure until estrus). However, Zimmerman et al., 1969 stated that when gilts are exposed to boars too early, the stimulus factor may be reduced such that the mean age at puberty may increase as compared to gilts exposed at a later age. Components of boar stimuli appears to be related to visual and auditory factors associated with the male as stated by Kinsey et al., 1976 and Zimmerman et al., 1974. 
Table.1 The mean age at puberty (Mean \pm S. E) in treatment and the control group

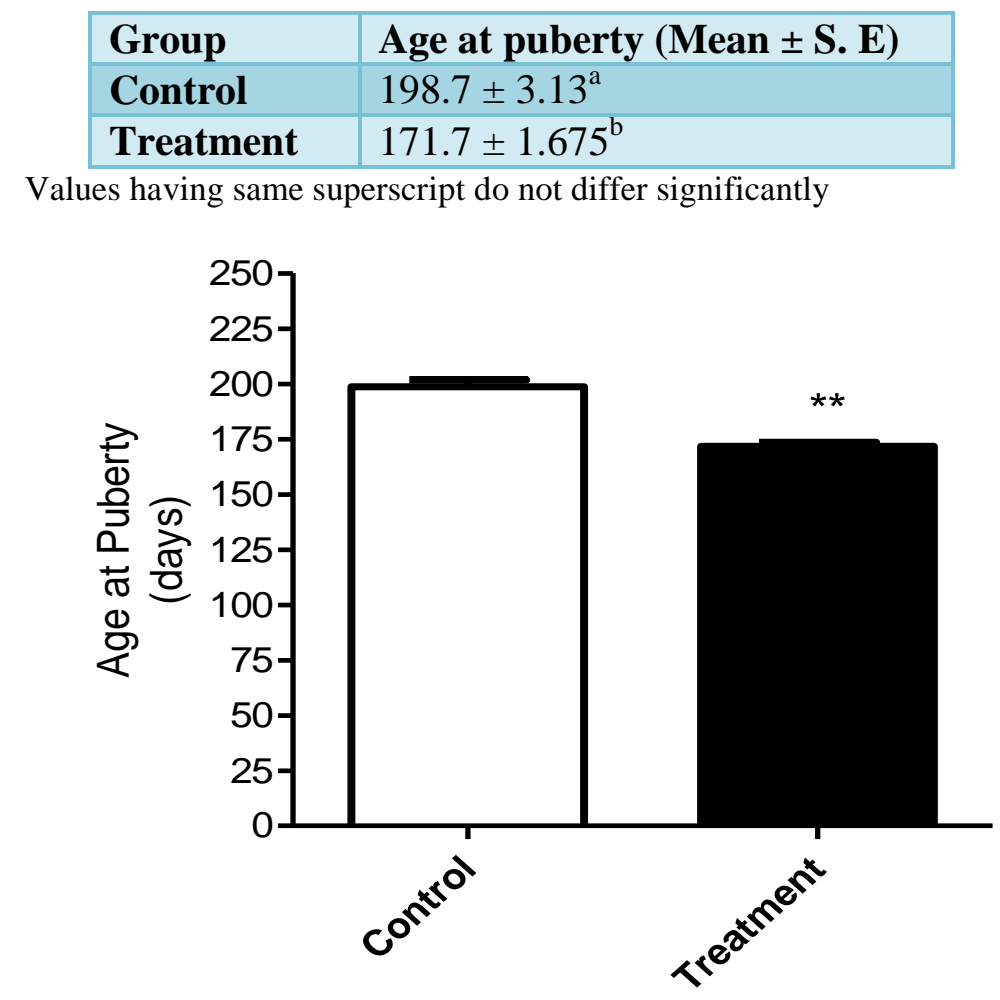

Fig.1 The mean age at puberty (Mean \pm S. E) in treatment and the control group

Other management techniques such as mixing gilts together or transporting gilts near the age when estrus would occur has been suggested to stimulate the onset of puberty by Zimmerman et al., (1974), Kinsey et al., (1976), Schiemann et al., (1976), Zimmerman et al., (1976).

The study reveals better reproductive performance in terms of attainment of puberty in improved pig breed Hampshire compared to local non-descript pigs under similar managerial conditions also stressing scope for breed improvement or upgradation of local pigs with improved varieties.

\section{Acknowledgement}

The authors are grateful for the support extended by the team of DEE, AAU, Jorhat for smooth conduct of the programme.

\section{References}

Brooks, P. H. and D. J. Cole. 1970. The effect of the presence of a boar on the attainment of puberty in gilts. J. Reprod. Fert.23:435.

Hughes, P. E. and D. J. Cole. 1976. Reproduction in the gilt: 2. Influence of gilt age at boar introduction on the attainment of puberty. Anim. Prod. 23: 89.

Kinsey, R. E., R. Carlson, C. Proud and D. R. Zimmerman. 1976. Influence of boar component stimuli on age at puberty in gilts. J. Anim. Sci. 43:1362.

Krikwood, R.N. and Thacker, P.A. (1988).Failure of an induced ovulation during lactation to improve sow or litter performance. Canadian J. Anim. Sci., 70: 135-138.

Lo, L.L.; Tsou, H.L. and Shen, K.H. (1985). 
Effects of reproductive performance of gilts by different feeding methods during growing period. Proc. 3rd AAAP Anim. Sci. Congr., 1:302-303

Mavrogenis, A.P. and Robinson, O.W. (1976). Factors affecting puberty in swine. Journal of Animal Science. 42: $1251-1255$

Robertson, G. L., R. H. Grummer, L. E. Casida and A. B. Chapman.195la. Age at puberty and related phenomena in outbred Chester White and Poland China gilts. J. Anim. Sci. 10:647.

Schiemann, C. A., D. C. England and W. H. Kennick. 1976. Initatingestrus in prepubertal confinement gilts. J. Anim. Sci. 43: 210. (Abstr. ).

Shyam J, Tripathi $\mathrm{H}$ and Balaraju BL. 2017.Economic contribution of backyard piggery in the livelihood security of tribal families of Assam. International Journal of Livestock Research, 7(2), 135-143.
Stewart, T. S., C. R. Long and T. C. Cartwright. 1976. Heterosis and combining ability for female puberty characters. J. Anim. Sci. 43:22. (Abstr.).

Thompson, L. H. and J. S. Savage. 1978. Age at puberty and ovulation rate in gilts in confinement as influenced by exposure to a boar. J. Anim. Sci. 47:1141.

Zimmerman, O.R., R. Carlson and B. Lantz. 1974. The influence of exposure to the boar and movement on pubertal development in the gilts. J. Anim. Sci. 39:230.

Zimmerman, D. R., P. Bourn and D. Donovan. 1976. Effect of 11 Transport Phenomena" stimuli and boar exposure on puberty in gilts. J. Anim. Sci. 42:1362.

Zimmerman, D. R., R. Carlson and L. Nippert. 1969. Age at puberty in gilts as affected by daily heat checks with a boar. J. Anim. Sci. 29:203 (Abstr.).

\section{How to cite this article:}

Chakraborty, A., B. C. Deka and Nath, L. K. 2020. Attainment of Puberty in Pigs under Local Managemental Conditions. Int.J.Curr.Microbiol.App.Sci. 9(04): 2539-2542.

doi: https://doi.org/10.20546/ijcmas.2020.904.304 